\title{
MEMÓRIAS DE UM SARGENTO DE MILÍCIAS EM HQ E OS MULTILETRAMENTOS NA ESCOLA
}

Renata Lopes da SILVA

Francine Fernandes Weiss RICIERI

\section{RESUMO}

Este artigo discute a multimodalidade e suas convergências com o ensino de língua portuguesa, a partir da análise de uma adaptação literária em quadrinhos de um clássico da literatura brasileira, o romance Memórias de um Sargento de Milícias. O estudo desse objeto tem como propósito verificar, a partir da comparação com o texto em prosa, quais recursos multimodais, próprios dos quadrinhos, foram mobilizados na sua produção e, ao final, discutir sua relevância para a prática dos multiletramentos na escola e indicar possíveis caminhos para sua aplicação em sala de aula.

PALAVRAS-CHAVE: Multimodalidade; Multiletramentos; Adaptação.

\section{MEMÓRIAS DE UM SARGENTO DE MILÍCIAS IN COMICS AND THE MULTILITERACIES AT SCHOOL}

\section{ABSTRACT}

This article discusses the multimodality and its convergences with the teaching of the Portuguese language, from the analysis of a comic literary adaptation of a classic of Brazilian literature, the novel Memórias de um Sargento de Milícias. The study of this object aims to verify, from the comparison with the prose text, which multimodal resources, typical of the comics, were mobilized in its production and, at the end, discuss its relevance to the practice of multiliteracies at school and indicate possible ways for your classroom application.

KEYWORDS: Multimodality; Multiliteracies; Adaptation.

\section{MEMÓRIAS DE UM SARGENTO DE MILÍCIAS EN CÓMICS Y MULTILETRAMENTOS EN LA ESCUELA}

\section{RESUMEN}

Este artículo a borda la multimodalidad y sus convergencias con la enseñanza de la lengua portuguesa, a partir del análisis de una adaptación literaria cómica de un clásico de la literatura brasileña, la novela Memórias de um Sargento de Milícias. El estudio de este objeto tiene como objetivo verificar, a partir de la comparación con el texto en prosa, qué recursos multimodales, típicos de los cómics, se movilizaron en su producción y, al final, discutir su relevancia para la práctica de los multiletramentos en la escuela e indicar posibles formas para su aplicación en el aula.

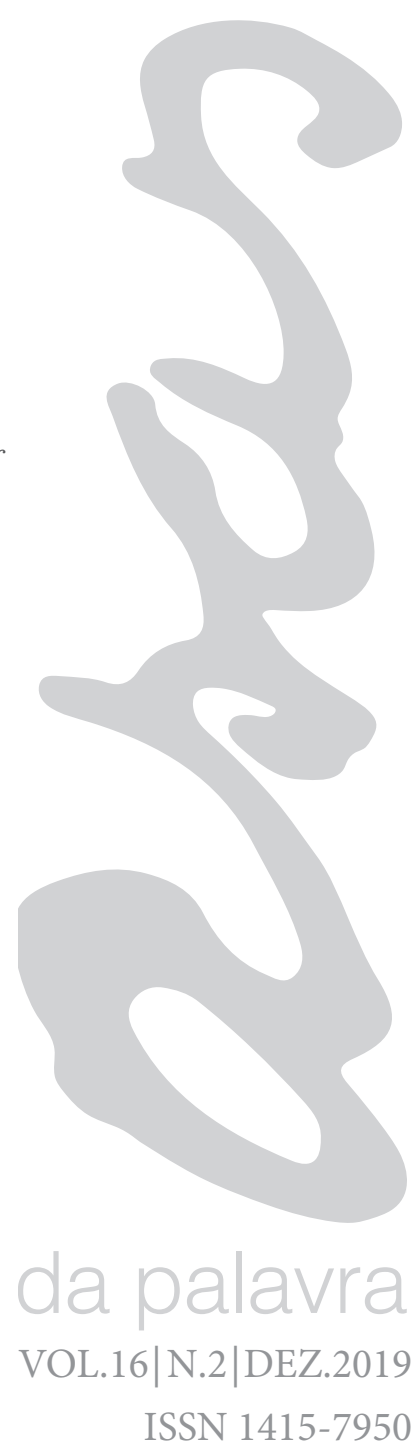

PALABRAS CLAVE: Multimodalidad; Multiletramentos; Adaptación. 


\section{PRIMEIRAS CONSIDERAÇÕES}

O que são obras clássicas? No primeiro capítulo do livro Por que ler os Clássicos, Italo Calvino apresenta quatorze possíveis respostas para essa questão. Dentre as conceituações reveladas pelo autor italiano, uma delas é pertinente para as reflexões desenvolvidas na sequência: "Um clássico é um livro que nunca terminou de dizer aquilo que tinha para dizer." (2007, p. 11, grifos do autor). É inegável a posição consagrada que os clássicos ocupam na escola. Por meio dela, eles se tornam familiares a muitos estudantes. Entretanto, o mero contato com essas obras canônicas não consolida, necessariamente, práticas de leitura efetivas durante suas trajetórias escolares. Esse fato impõe um grande desafio aos professores de língua portuguesa e suscita um questionamento: há outros modos de ler as obras clássicas atualmente?

Em tempos de intensa aceleração tecnológica, a integração de variados modos de linguagem torna mais complexa a constituição dos textos que permeiam o cotidiano dos sujeitos. Nesse sentido, elementos linguísticos e não linguísticos entram em confluência e constituem os chamados textos multimodais, objetos de interesse de distintas teorias dos estudos linguísticos. As adaptações literárias em quadrinhos são profícuas para a discussão dessas recentes composições textuais multifacetadas. Assim, integrado a esse debate, este artigo analisa uma adaptação quadrinística, elaborada por Rodrigo Rosa (arte) e Ivan José de Azevedo Fontes (roteiro) ${ }^{1}$, de um clássico da literatura brasileira do século XIX, Memórias de um Sargento de Milícias (1852-1853), obra escrita por Manuel Antônio de Almeida (1830-1861). O estudo desse objeto tem como propósito verificar, a partir da comparação com o texto em prosa, quais recursos multimodais, próprios dos quadrinhos, foram mobilizados na sua produção e, ao final, discutir sua relevância para a prática dos multiletramentos na escola e indicar possíveis caminhos para sua aplicação em sala de aula.

\section{DISCUSSÃO TEÓRICA}

As relações entre imagem e palavra têm sido cada vez mais 1 O roteirista será referido, a debatidas no campo dos estudos linguísticos e nos seus diálogos com partir de agora, como Ivan Jaf, apenas, seguindo o modo como ele é nomeado nas capas das consequentemente, com a maior variabilidade de recursos editoriais adaptações que já produziu. disponíveis, a produção de textos compostos por múltiplos modos de linguagem aumenta. Esse fato traz uma implicação teórica: a necessidade 
REVISTA DO PROGRAMA DE PÓS-GRADUAÇÃO EM COMUNICAÇÃO, LINGUAGENS E CULTURA DA UNIVERSIDADE DA AMAZÔNIA

de ampliação do conceito de texto. Este deve ser apreendido pela ótica dessa diversidade constitutiva, sendo entendido para além de um aglomerado de frases. Nesse sentido, em Produção textual, análise de gêneros e compreensão, Luiz Antônio Marcuschi (2008), baseado nas proposições de Beaugrande, afirma: “[...] o texto é construído numa orientação de multissistemas, ou seja, envolve tanto aspectos linguísticos como não-linguísticos no seu processamento (imagem, música) e o texto se torna em geral multimodal." (2008, p. 80, grifos do autor).

Esse alargamento do conceito de texto para além dos aspectos intrinsecamente verbais e a importância de se considerar as estruturas visuais também dialogam com o desenvolvimento das investigações científicas do campo da Semiótica Visual e, em particular, com a Gramática do Design Visual, proposta no ano de 1996, pelos professores Gunther Kress e Theo Van Leeuwen. O objetivo da GV era suplantar a análise de imagens de modo sistemático, ou como ressalta a pesquisadora Danielle Almeida (2009), no livro Linguística aplicada: um caminho com diferentes acessos: "[...] propor um padrão de descrição estética das imagens, partindo do pressuposto de que os seus elementos internos são combinados entre si para comunicar um "todo coerente" e, dessa forma, expressar significados distintos." (2009, p. 174, grifos da autora).

Embora esses apontamentos iniciais ressaltem o vínculo entre o texto e a imagem, a compreensão sobre o conceito de multimodalidade também deve ser estendida. No livro Multimodal Discours The Modes and Media of Contemporary Communication, Kress e Van Leeuwen (2001) definem a multimodalidade como: "the use of several semiotic modes in the design of a semiotic product or event" (2001, p. 20). Os referidos modos são: "semiotic resources which allow the simultaneous realisation of discourses and types of (inter) action." (2001, p. 22). Eles incluem recursos semióticos diversificados e que estão presentes nas mais variadas manifestações linguísticas. Imagens, cores, movimentos, layouts, fontes, espaçamento, distribuição da informação em diferentes espaços, sons, gestos, expressões faciais, fala ou escrita são alguns exemplos.

Examinar as possibilidades de recontar uma história por outros modos de linguagem parece fundamental para a formação dos alunos do Ensino Básico, visto que, como argumenta Angela Paiva Dionísio 
(2011) no livro Gêneros textuais: reflexões e ensino, essa prática permite que eles "observem princípios de organização de textos multimodais." (2011, p. 141). Desse modo, multimodalidade e multiletramentos são conceitos interligados. O termo "multiletramentos" surgiu em um manifesto, intitulado A Pedagogy of Multiliteracies e publicado pelos pesquisadores do Grupo de Nova Londres (GNL) em 1996. A preocupação dos estudiosos era justamente propor que a diversidade cultural e a multiplicidade de textos emergentes fossem integradas às práticas de ensino. Roxane Rojo (2012), em Multiletramentos na escola, também enfatiza que os textos multimodais são: "textos compostos de muitas linguagens (ou modos, ou semioses) e que exigem capacidades e práticas de compreensão e produção de cada uma delas (multiletramentos) para fazer significar." (2012, p. 19).

Esse quadro geral dos princípios elementares da multimodalidade embasa as discussões sobre o corpus. Afinal, como aponta Dionísio (2011): "Os meios de comunicação de massa escritos e a literatura são dois espaços sociais de grande produtividade para a experimentação de arranjos visuais." (2011, p. 135). No caso das adaptações literárias em quadrinhos, em particular, esse arranjo visual citado pela autora advém de um processo adaptativo (termo explicado adiante). $\mathrm{O}$ romance em prosa - predominantemente verbal - é revestido, na versão em quadrinhos, por uma linguagem imagética que o reconstrói. Como afirma Cristina de Oliveira (2014), em capítulo da obra Quadrinhos e literatura: diálogos possíveis:

[...] numa adaptação de um texto literário para o cinema os signos linguísticos são convertidos para imagens áudio visuais, no caso da quadrinização de obras da literatura ou o diálogo entre ambos os meios, ocorre a transformação da informação verbal literária em uma narrativa construída por meio de uma sequencialidade de imagens, na qual a relação entre as linguagens verbal e não verbal se torna mais importante do que cada uma considerada separadamente. (2014, p. 40)

Compreender a concepção de adaptação adotada é um fundamento importante para relacioná-la com a multimodalidade. Em Uma Teoria da Adaptação, Linda Hutcheon (2013) define as adaptações a partir de um olhar duplo, vendo-as enquanto processo e produto. A primeira denominação revela: "a adaptação sempre envolve tanto uma (re)interpretação quanto uma (re)criação; dependendo da perspectiva, VOL. 16 | N.2 | DEZ.2019 isso pode ser chamado de apropriação ou recuperação.” (2013, p. 29). A 
REVISTA DO PROGRAMA DE PÓS-GRADUAÇÃO EM COMUNICAÇÃO, LINGUAGENS E CULTURA DA UNIVERSIDADE DA AMAZÔNIA

segunda, por sua vez, sinaliza: “[...] entidade ou um produto formal, a adaptação é uma transposição anunciada e extensiva de uma ou mais obras em particular." (2013, p. 29, grifos da autora).

$\mathrm{O}$ ato de adaptar faz referência a um texto preexistente e, ao mesmo tempo, modifica esse texto. Assim, a adaptação do romance Memórias de um Sargento de Milícias está, declaradamente, atada ao passado, porém, ao recuperar o texto antecessor pela linguagem dos quadrinhos, também ganha autonomia: “[...] a adaptação, do ponto de vista do adaptador, é um ato de apropriação ou recuperação, e isso sempre envolve um processo duplo de intersecção e criação de algo novo." (2013, p. 47). Examinar os recursos multimodais utilizados para recuperar o texto clássico é um meio de compreender como esse processo de criação está estruturado, sem pautar-se em um critério de fidelidade, abordagem frequentemente adotada nos estudos dessa natureza.

Essa passagem de um texto A para um texto B - ou transposição, para utilizar um termo já citado por Hutcheon (2013) - é realizada pelos adaptadores. Os distintos modos semióticos utilizados por eles não são aleatórios. Na perspectiva de Umberto Eco (2007), explicada no capítulo "Quando muda a matéria", da obra Quase a mesma coisa, esse processo de transmutar "[...] agrega significados ou torna relevantes conotações que não o eram originalmente." (2007, p. 382). Esse fato decorre de duas razões.

A primeira é a posição de Rodrigo Rosa e Ivan Jaf enquanto leitores do romance, antes mesmo de serem propriamente adaptadores. A leitura, na perspectiva de Ingedore Koch e Vanda Elias (2008) envolve, dentre outros fatores, a interação autor-texto-leitor, sendo "um trabalho ativo de compreensão e interpretação do texto, a partir de seus objetivos, de seu conhecimento sobre o assunto, sobre o autor, de tudo o que se sabe sobre a linguagem etc." (2008, p. 12). A segunda razão decorre da primeira e tem relação com a ponderação exposta por Eco (2007). Desse modo, relacionando o fenômeno da adaptação com os princípios teóricos da multimodalidade na perspectiva da sociossemiótica, é possível entender que os leitores/adaptadores fazem escolhas. Como argumentam Sônia Pimenta e Zaíra Bomfante dos Santos (2017), tais escolhas referem-se aos "processos de orquestração - seleção/organização - da pluralidade de signos em diferentes modos, dentro de uma configuração, para formar um arranjo 
coerente no estabelecimento das relações com o leitor.” (2017, p. 387).

As semioses presentes na adaptação derivam, como esperado, das especificidades das histórias em quadrinhos. A relação entre imagem e palavra é característica elementar de todo o potencial expressivo desse tipo de texto. Além disso, talvez sejam os quadros sequenciados e os balões que tornem as histórias em quadrinhos ainda mais identificáveis à recepção leitora. O pesquisador Francisco O. Dourado Veloso (2014), ao estudar as HQs pela abordagem sociossemiótica, identifica outro elemento como crucial: os recordatários, que contêm as falas do narrador onisciente - também chamados de legenda. Tendo em vista esses elementos, o autor alinha a arte sequencial e a multimodalidade no mesmo plano, afirmando: "HQs são artefatos multimodais complexos, cujas páginas em branco servem como uma tela para disposição de elementos que darão forma à narrativa." (2014, p. 169).

Em obra intitulada $A$ leitura dos quadrinhos, Paulo Ramos (2012) apresenta, didaticamente, aspectos estruturais das HQs e também enfatiza a importância de ler essa produção pelos seus aspectos multimodais: "Ler quadrinhos é ler sua linguagem, tanto em seu aspecto verbal quanto visual (ou não verbal).” (2012, p. 14). Essa obra será relevante ao processo de análise. Além dela, o livro Quadrinhos e arte sequencial: princípios e práticas do lendário cartunista, de Will Eisner (2010), será mencionado.

\section{O ROMANCE E SUA ADAPTAÇÃO}

\subsection{Contextualização de corpus}

O romance de Manuel Antônio de Almeida foi publicado inicialmente em folhetim, com tiragem aos domingos, entre 27 de junho de 1852 e 31 de julho de 1853, no suplemento intitulado "A Pacotilha", pertencente ao jornal carioca Correio Mercantil. O enredo traz como cenário o Rio de Janeiro de 1808, período da vinda da família real portuguesa ao Brasil. A história encena o amor desajeitado entre Leonardo-Pataca e Maria da Hortaliça, iniciado em uma viagem de navio de Portugal ao Brasil, por meio "pisadelas e beliscões". É desse amor que nasce o genioso Leonardinho. Ao ser abandonado pelos pais, o menino fica sob a tutela de seu bondoso padrinho e pratica diabruras diversas. Com a morte do patrono, leva a vida como um malandro, caminhando à própria sorte e tirando proveito de situações favoráveis. Esse modo cambaleante perdura até a fase adulta, quando ocorre sua 
nomeação a Sargento de Milícias e seu casamento com Luisinha, moça que conheceu na juventude.

O romance ocupa posição canônica na literatura nacional, sendo indicado para leitura nas escolas. A adaptação, por sua vez, foi elaborada por uma parceria entre o cartunista, ilustrador e quadrinista Rodrigo Rosa e o escritor, redator e editor brasileiro Ivan Jaf, ambos igualmente muito premiados em suas áreas de atuação. Em 2010, a primorosa criação foi apresentada pela Editora Ática, como integrante da coletânea "Clássicos Brasileiros em HQ", da qual fazem parte outras duas adaptações realizadas pela dupla: Dom Casmurro e $O$ Cortiço. Os paratextos trazidos pela edição selecionada para compor este artigo demonstram, em parte, a condução do processo adaptativo. Elementos multimodais podem ser entrevistos, ainda que minimamente, pela descrição dos editores da adaptação ao trabalho feito por Rosa e Jaf (2010):

Nesta adaptação em HQ, o romance ficou ainda mais divertido nas sequências de cenas e nas falas muito bem escolhidas por Ivan Jaf. Rodrigo Rosa deu rostos e movimentos marcantes aos personagens, evidenciando seus traços humorísticos e caricatos. Para compor a atmosfera do Rio de Janeiro do começo do século XIX, o desenhista fez muitas pesquisas. Entre as referências destacam-se as aquarelas do pintor francês Jean Baptiste Debret, que retratou o cotidiano da população carioca do tempo de dom João VI - quando acontece a história. (2010, p. 04, grifos meus)

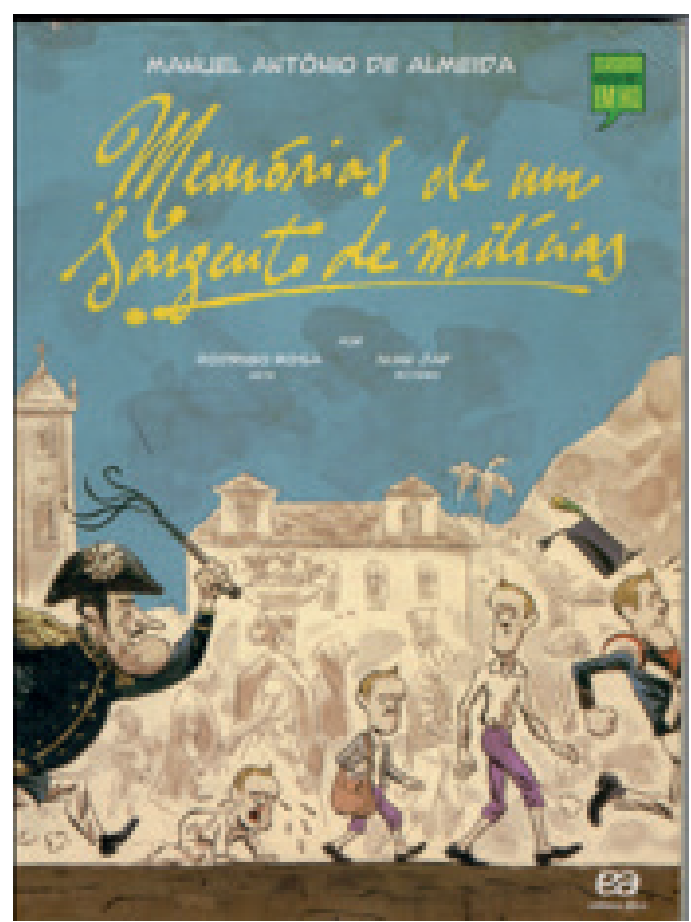


Além da capa da HQ, a análise a ser apresentada na sequência limita-se a duas passagens importantes do romance. São elas: 1) o nascimento do protagonista do romance, Leonardinho, e o relato da história de seus pais e 2) o casamento de Leonardinho com Luisinha, o primeiro amor de sua mocidade. As duas passagens correspondem, respectivamente, ao primeiro e ao último capítulo do romance. Os trechos da obra original serão recuperados, de modo a confrontálos com os quadros sequenciados. Portanto, o método empregado é comparativo. A adaptação e suas recriações - que sobressaltam ainda mais a multimodalidade - serão o foco. O processo analítico é iniciado pela capa, posta acima.

A relação intrínseca entre imagem e palavra, discutida com afinco na primeira seção, tem notoriedade na capa da HQ. Ao topo, o nome do autor da obra original é apresentado ao público. Ao lado direito, em formato de balão, está a identificação da coleção a qual pertence a obra, em cor verde. O nome da obra original é escrito em cor amarela, com forte impacto caligráfico, remetendo a fontes delineadas com auxílio da pena e do tinteiro, típicos do século XIX. Os nomes dos adaptadores aparecem logo abaixo, em tamanhos menores quando comparados ao nome do autor romanesco. A capa sinaliza o quanto o livro mantém uma ligação declarada com o texto antecessor.

Em sua organização estrutural, os elementos de maior proeminência são as ilustrações. Elas podem ser vislumbradas em dois planos. No plano de fundo, o cenário carioca do século XIX e as camadas populares da época são encenados, em cor bege e de aspecto opaco. Essa representação do período histórico pode ser apreendida por meio dos elementos visuais, como salienta Ramos (2012): “O signo visual icônico é o elemento central para se perceber o momento histórico (por meio de roupas, cenários)." (2012, p. 132). A cor bege tem aspecto envelhecido, remetendo a um período longínquo. Essa observação sublinha a importância que as cores desempenham no processo de produção de sentidos dos textos multimodais, afinal, elas são: "signos plásticos que contêm informação ora mais relevante para a compreensão do texto narrativo, ora menos." (RAMOS, 2012, p. 87).

No primeiro plano, está o protagonista do romance em quatro etapas de sua vida: bebê; criança; jovem e adulto. A percepção da passagem do tempo é ilustrada e o envelhecimento do protagonista é posto em cena imageticamente. Trata-se de uma sucessão temporal 
produzida por meio de elipse, conforme discute Ramos (2012, p. 131). A mudança corpórea do personagem e o desenvolvimento de suas habilidades motoras também acentuam essa passagem do tempo. O efeito de sentido produzido é: a história a ser contada por meio de quadros sequenciados tratará, especificamente, das peripécias desse sujeito. O leitor pode inferir essa informação com base na observação atenta desses elementos multimodais e na sua própria experiência com o tempo, pois:

A capacidade de expressar a passagem do tempo é decisiva para o sucesso de uma narrativa visual. É essa dimensão da compreensão humana que nos habilita reconhecer e compartilhar emocionalmente a surpresa, o humor, o terror e todo o âmbito da experiência humana. É nesse teatro da nossa compreensão que o narrador gráfico exercita sua arte. No cerne do uso sequencial de imagens com o intuito de expressar a passagem do tempo está o caráter compartilhado da sua percepção. (EISNER, 2010, p. 24)

A sugestão de movimento - produzida justamente pelos atos de engatinhar, caminhar e correr - é motivada pela perseguição do Major Vidigal, autoridade responsável por manter a ordem (espécie de policial) e aplicar penas aos desordeiros, como Leonardinho.

\subsubsection{Origem, nascimento e hora do batismo (parte inicial)}

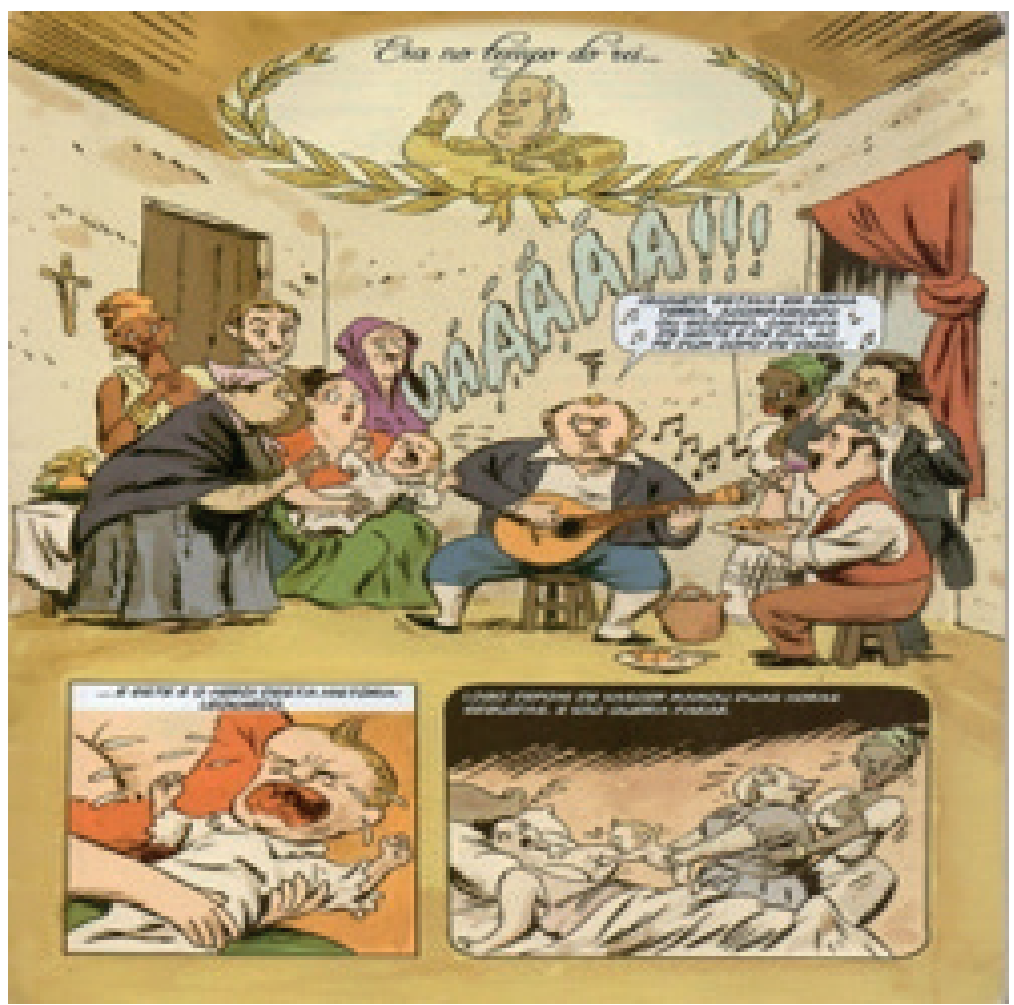

Figura 2 - Primeira página da adaptação de Rosa e Jaf (2010, p. 05). 
Na primeira página da adaptação, em itálico, na parte superior da página, a frase de abertura do romance é recuperada: Era no tempo do Rei. Envolta por desenhos de folhas de louro, dignas de requinte e opulência, a figura de Dom João VI é apresentada ao leitor, constituindo uma espécie de saudação àquele que está na iminência de adentrar uma história antiga, localizada temporalmente entre 1808-1822. Tanto a frase quanto a representação imagética do rei são complementares e constituem relações intertextuais. Koch e Elias (2008), ao descreverem a intertextualidade, argumentam que "identificar a presença de outro(s) texto(s) em sua produção escrita depende e muito do conhecimento do leitor, do seu repertório de leitura. Para o processo de compreensão e produção de sentido, esse conhecimento é de fundamental importância." (2008, p. 78). No caso da adaptação, essa relação entre textos é um princípio constitutivo. Porém, em alguns momentos, a referência ao texto original é mais explícita.

Após a frase de abertura, o enredo de Manuel Antônio de Almeida realiza uma extensa descrição sobre os meirinhos (oficiais de justiça da época). Os adaptadores optam por suprimir esse trecho - provavelmente por conta da extensão - e iniciam a HQ a partir de um momento de festividade do romance, descrito ao final do primeiro capítulo. Trata-se do batismo do pequeno Leonardo. No romance, o narrador descreve a cena da seguinte maneira:

\footnotetext{
Chegaram uns rapazes de viola e machete: o Leonardo [pai], instado pelas senhoras, decidiu-se a romper a parte lírica do divertimento. Sentou-se num tamborete, em um lugar isolado da sala, e tomou uma viola. Fazia um belo efeito cômico vê-lo, em trajes do oficio, de casaca, calção e espadim, acompanhando com um monótono zum-zum nas cordas do instrumento o garganteado de uma modinha pátria. Foi nas saudades da terra natal que ele achou inspiração para o seu canto, e isto era natural a um bom português, que o era ele. A modinha era assim: Quando estava em minha terra/Acompanhado ou sozinho/Cantava de noite e de dia/Ao pé dum copo de vinho! (ALMEIDA, 1997, p. 16, grifos do autor, acréscimo meu)
}

$\mathrm{Na}$ adaptação, somente a cantoria é mantida no primeiro quadro. Sentado ao centro e devidamente trajado com as roupas do ofício seguindo a descrição do romance -, o pai do protagonista canta. A voz é representada pelo tradicional balão de fala das HQs. Dentro deste, VOL. 16 | N.2 | DEZ. 2019 a letra da modinha portuguesa é grafada em itálico, construindo mais 
representado visualmente por meio de notas musicais, localizadas dentro do balão e próximas da viola. O modo sonoro, nos quadrinhos, é visual. O leitor tem suas percepções sobre o enredo ampliadas.

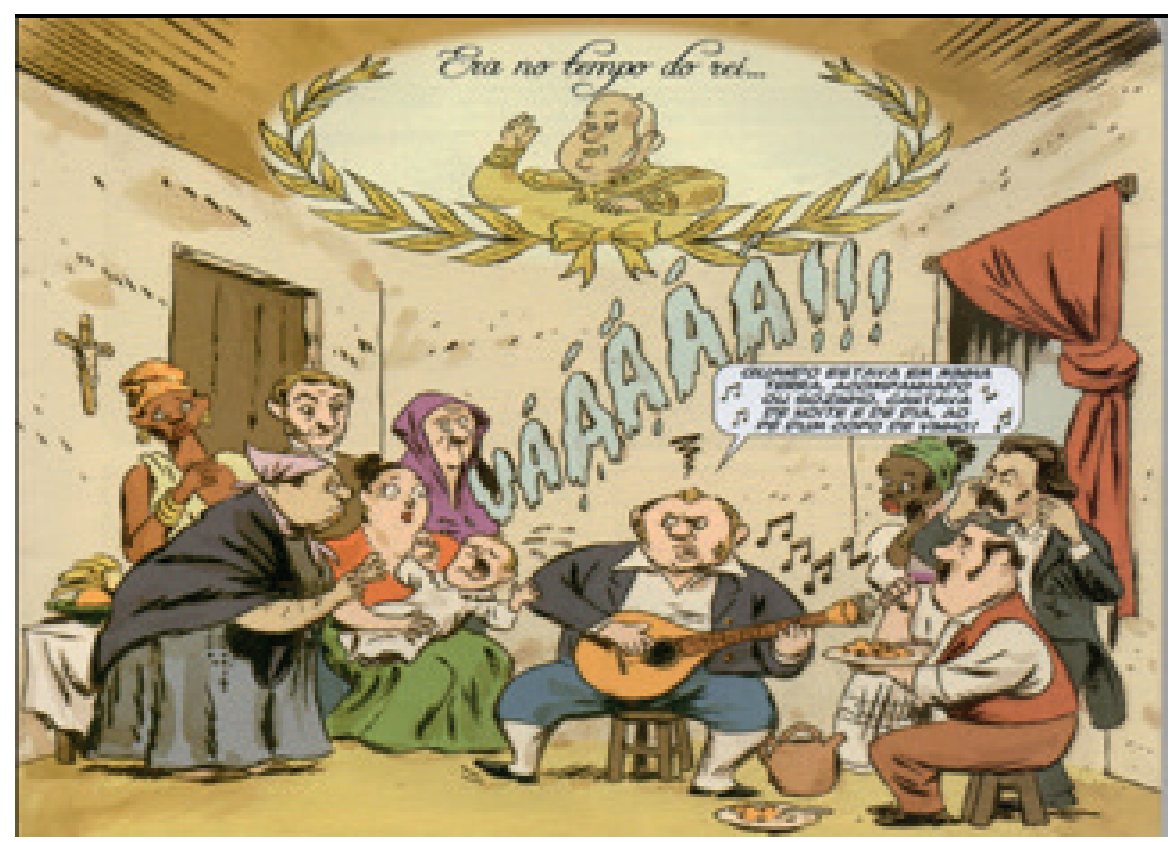

Restrita ao espaço doméstico, a celebração, quando ilustrada por Rosa (2010), conta com a presença de outros personagens do romance: Maria da Hortaliça, que segura o seu filho; o padrinho do menino, à direita do patriarca da família e, por último, a madrinha, em pé, ao lado da saloia e do recém-batizado. Ao invés dos "rapazes de viola e machete" descritos pela prosa romanesca, a adaptação conta com a presença de outros convidados ilustres, e que não são, propriamente, “dalém mar": à esquerda, o pintor Debret é representado. Como mencionado anteriormente, o processo adaptativo engendrado na obra teve inspiração nos quadros dele:

Rodrigo Rosa se baseou nas aquarelas de Debret para compor cenários, figurantes e muitos outros detalhes ao longo desta HQ. O próprio Debret aparece no primeiro quadro da $\mathrm{HQ}$, atrás de comadre e da Maria da Hortaliça, olhando impressionado para o chorão Leonardo. (Editores da adaptação, 2010, p. 79)

À direita, está o autor do romance, Manuel Antônio de Almeida. Esses sutis detalhes, além de demonstrarem a multimodalidade envolvida na elaboração do livro, podem oferecer ao professor discussões profícuas sobre outras ampliações imagéticas possibilitadas pelos quadrinhos.

No romance, a apresentação musical ocorre em paralelo ao
Figura 3 - Primeiro quadro da adaptação de Rosa e Jaf (2010, p. 05).

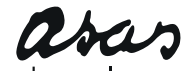

da palavra 
choro do "herói da história": "Foi executada com atenção e aplaudida com entusiasmo, somente quem não pareceu dar-lhe todo o apreço foi o pequeno, que obsequiou o pai como obsequiara ao padrinho, marcandolhe o compasso a guinchos e esperneios" (ALMEIDA, 1997, p. 16). A algazarra é representada por um importante recurso multimodal: a onomatopeia “uááááá!!!”. Sobre esse recurso, Ramos (2012) comenta: “Talvez seja de Cirne (1970) a mais sintética explicação do que sejam as onomatopeias nos quadrinhos: 'O ruído, nos quadrinhos, mais do que sonoro, é visual."” (CIRNE, 1970 apud RAMOS, 2012, p. 78). O formato dela é aquoso, tal como as lágrimas do protagonista:

\footnotetext{
É aqui que o potencial expressivo do artista de quadrinhos se evidencia mais nitidamente. É isso, afinal, a arte da narrativa gráfica. A codificação, nas mãos do artista, transforma-se num alfabeto que servirá para expressar certo contexto, tecendo toda uma interação emocional. (EISNER, 2010, p. 09-10)
}

O incômodo dos presentes diante do alarido também é ainda mais visível na HQ. $\mathrm{O}$ aborrecimento dos convidados é mostrado por meio de outros elementos quadrinísticos: o redemoinho acima da cabeça de Leonardo, os olhos arregalados dos convidados, o ato de tapar os ouvidos feito pelo autor do romance e a postura benevolente da comadre, que se curva para prestar ajuda à Maria. Esses são aspectos que reforçam os "guinchos e esperneios", termos usados por Almeida (1997). Desse modo, a situação desagradável possui, nos quadrinhos, um grande apelo visual, de modo que: "As expressões faciais e as metáforas visuais se somam aos gestos dos personagens e à postura do corpo." (RAMOS, 2012, p. 114). O berreiro também é ressaltado pelo close up, conceito utilizado por Ramos (2012) para descrever momentos nos quais há essa aproximação de plano, pormenorizando detalhes, nesse caso, o protagonista, descrito como o "herói da história". O efeito de sentido produzido pelo uso desse plano é a aproximação do protagonista ao leitor, tornando-os mais íntimos.

Os quadros de três a dez remetem ao período anterior ao batismo. Eles contam a história dos pais do menino. O recuo temporal é concebido, como ocorre na capa da HQ, pelo uso das cores. Elas tornam-se mais foscas, como um pergaminho antigo. O formato da linha que demarca o quadrinho também é alterado: 
que as ações contidas no quadrinho estão no presente. O flashback (mudança de tempo ou deslocamento cronológico) muitas vezes é indicado por meio da alteração do traçado do requadro. O traçado sinuoso ou ondulado é o indicador mais comum de passado. (EISNER, 2010, p. 44, grifo do autor)

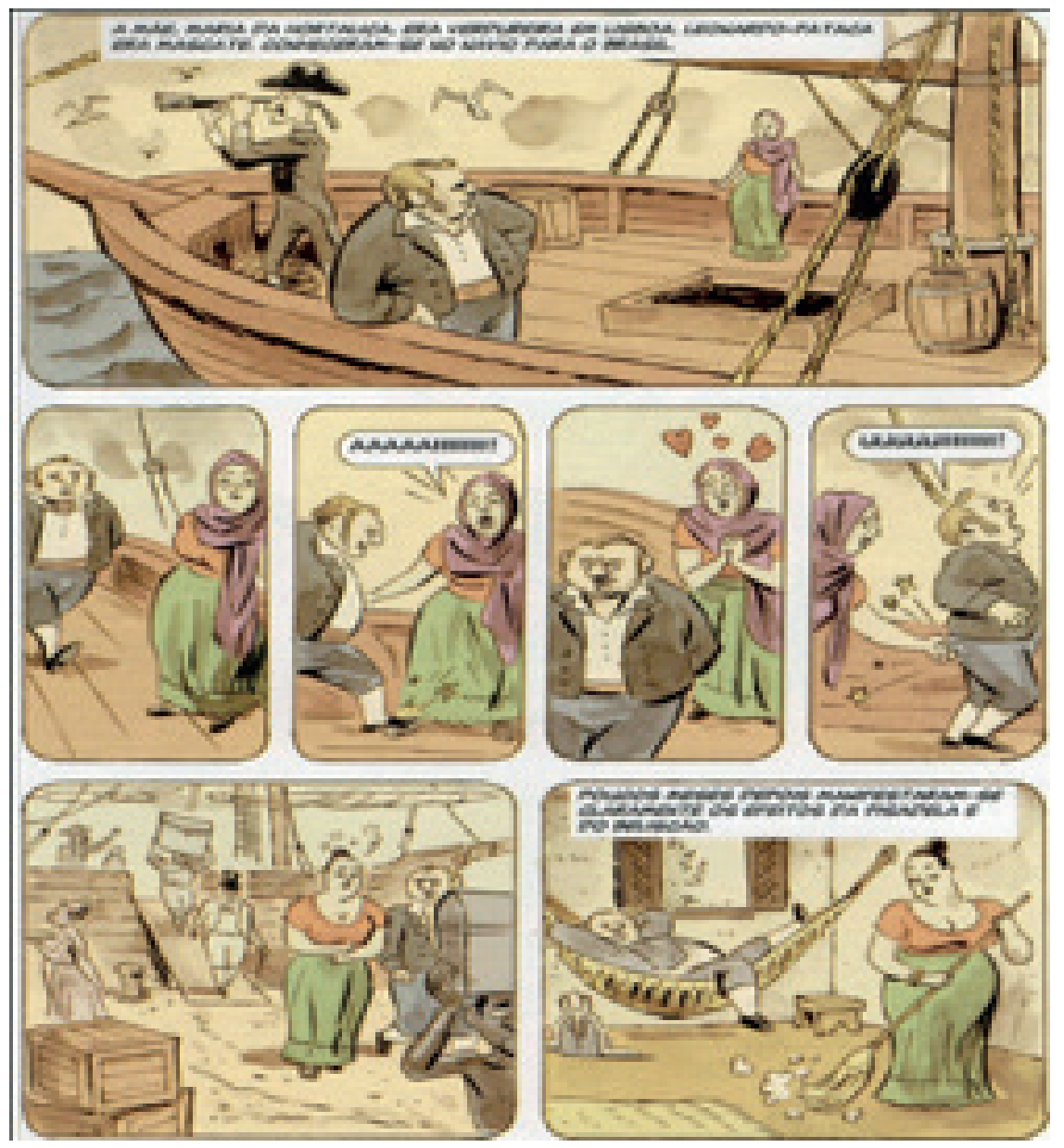

Figura 4 - Quadros de 03 a 10 da adaptação de Rosa e Jaf (2010, p. 06).

No quadro quatro, a ambientação muda. Leonardo-Pataca, esgueirado à beira de um navio, observa Maria da Hortaliça. O comandante da embarcação também é retratado de modo perspicaz, sugerindo uma triangulação entre os presentes (afinal, mais tarde, ele protagonizaria uma relação amorosa com a moça que findaria na separação do casal prestes a se formar). Em outras palavras, o capitão é posto em cena de forma sutil, como algo encoberto, mas perceptível ao leitor atento, afinal. No texto em prosa, a presença desse comandante ainda não é comentada. Ao ser colocado na HQ, os adaptadores parecem antecipar ou descobrir algo que, no romance, seria dito mais a frente. Esse fato aponta para a diferença entre os modos verbal e visual e para uma constatação de Eco (2007): "se o texto original propunha alguma coisa como inferência implícita, ao torná-la explícita o texto foi certamente interpretado, levando a fazer 
Figura 5 - Pisadelas e beliscões da adaptação de Rosa e Jaf (2010, p. 06).

"a descoberto" algo que originalmente ele pretendia manter implícito." (2007, p. 392, grifos do autor).
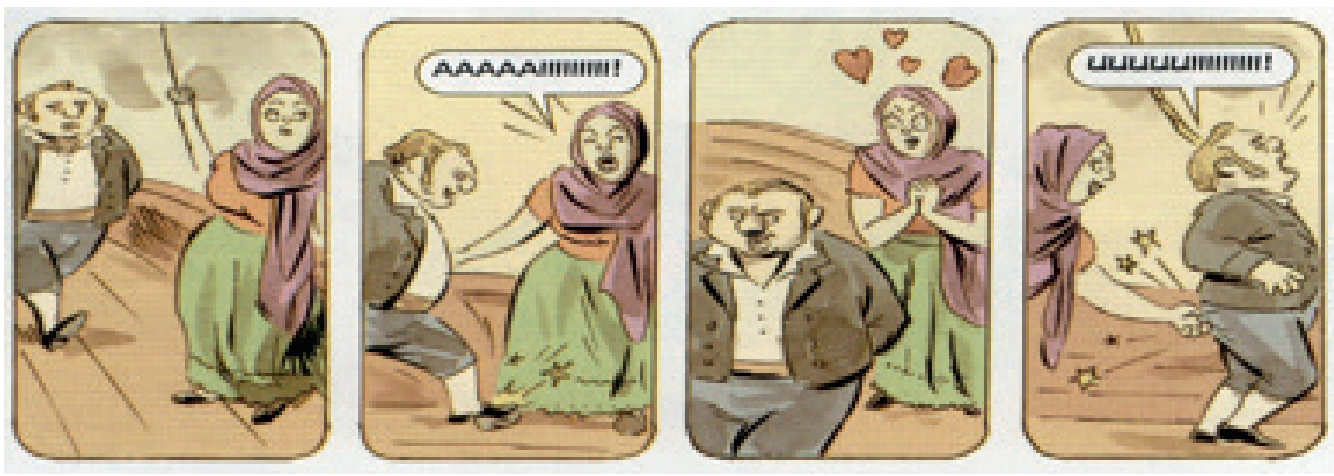

Pisadelas e beliscões são mantidos e merecem ser comentados à parte. As interjeições e os corações colocados nos quadros fazem com o que o leitor depreenda o sentido da cena: o nascimento de um amor marítimo, iniciado de modo risível, como também ocorre no romance:

Ao sair do Tejo, estando a Maria encostada à borda do navio, o Leonardo fingiu que passava distraído por junto dela, e com o ferrado sapatão assentou-lhe uma valente pisadela no pé direito. A Maria, como se já esperasse por aquilo, sorriu-se como envergonhada do gracejo, e deu-lhe também em ar de disfarce um tremendo beliscão nas costas da mão esquerda. Era isto uma declaração em forma, segundo os usos da terra: levaram o resto do dia de namoro cerrado; ao anoitecer passou-se a mesma cena de pisadela e beliscão, com a diferença de serem desta vez um pouco mais fortes; e no dia seguinte estavam os dois amantes tão extremosos e familiares, que pareciam sê-lo de muitos anos. (ALMEIDA, 1997, p. 15)

$\mathrm{Na}$ adaptação, a técnica da concisão de trechos mais descritivos ou elaborados em discurso indireto é usada com vigor. Com alto apelo visual, a leitura torna-se mais rápida, comparada ao texto em prosa. Outro exemplo para demonstrar esse princípio de economia está na construção da imagem do protagonista:

[...] teve a Maria um filho, formidável menino de quase três palmos de comprido, gordo e vermelho, cabeludo, esperneador e chorão; o qual, logo depois que nasceu, mamou duas horas seguidas sem largar o peito. E este nascimento é certamente de tudo o que temos dito o que mais nos interessa, porque o menino de quem falamos é o herói desta história. (ALMEIDA, 1997, p. 15)

A postura caricata de um herói às avessas é reconfigurada pela imagem. Além de chorar de modo exacerbado (quadro 02), ele mama, com afinco, por duas horas, impedindo que a força física de duas 
personagens o interrompam (quadro 03). Essas ações desmedidas, já articuladas no romance, ganham traços caricatos de uma personagem desproporcional (em sentido físico, dado o tamanho da cabeça em relação ao corpo). A comicidade continua instaurada. É possível afirmar, desse modo: "Personagens cômicos tendem a possuir falhas de comportamento e um aspecto visual mais caricato [...]." (RAMOS, 2012, p. 125). Por isso, esse primeiro momento analisado é oportuno, sobretudo a primeira página, porque ela apresenta Leonardo: “A primeira página de uma história funciona como uma introdução [...]. Ela é um trampolim para a narrativa, e, para a maior parte das histórias, estabelece um quadro de referência." (EISNER, 2010, p. 64).
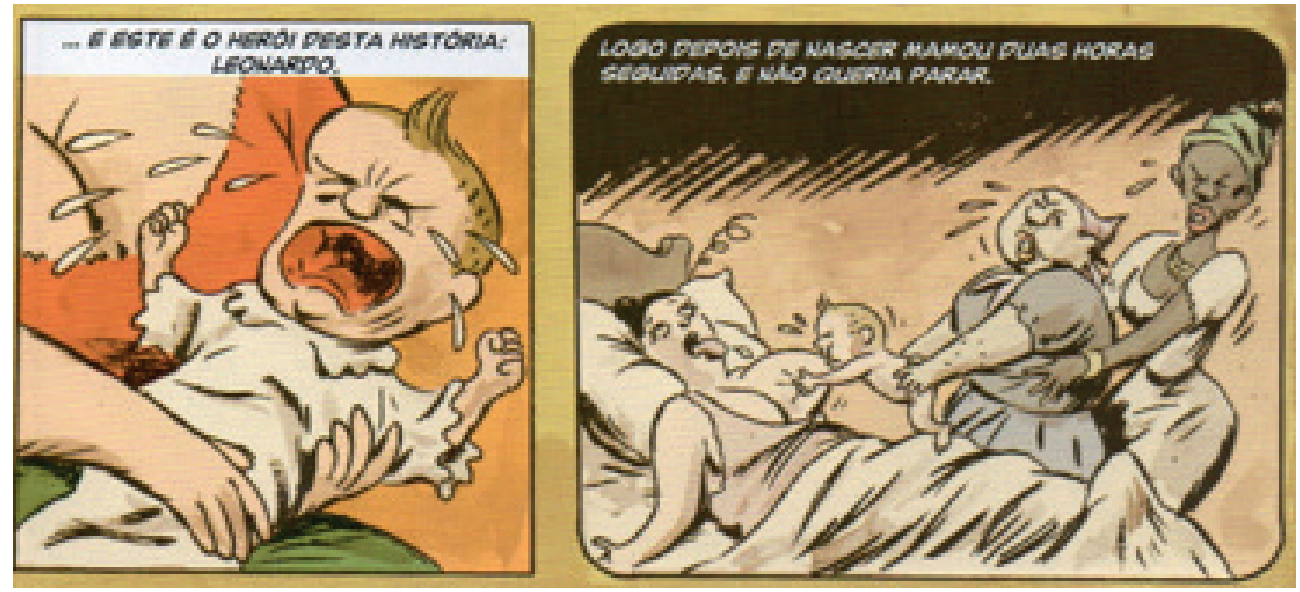

Figura 6 - Quadros 02 e 03 da adaptação de Rosa e Jaf (2010, p. 05).

\subsubsection{O casamento com Luisinha (parte final)}

Passado o tempo indispensável do luto [pela morte de José Manuel, ex-marido de Luisinha], o Leonardo, em uniforme de sargento de milícias, recebeu-se na Sé com Luisinha, assistindo à cerimônia a família em peso. Daqui em diante aparece o reverso da medalha. Seguiu-se a morte de D. Maria, a do Leonardo-Pataca, e uma enfiada de acontecimentos tristes que pouparemos aos leitores, fazendo aqui ponto-final. (ALMEIDA, 1997, p. 192, acréscimo meu)

A penúltima página da adaptação ilustra o casamento de Leonardo com Luisinha, retomando o parágrafo final do romance. "A família em peso", descrita por Almeida (1997) é representada, pela imagem, com todas as personagens que fizeram parte da trajetória do rapaz. Nessa representação narrativa, todos olham para os noivos. Leonardinho aparece mais velho e em trajes oficiais. A roupa, enquanto signo plástico, como aponta Ramos (2012), reforça a ideia da nomeação do protagonista a sargento de milícias, ofício posto no título do romance. 
Não há quadros nessas últimas duas páginas. A ausência de enquadramento (ou moldura) torna a composição dessas páginas finais distinta das anteriores. $\mathrm{O}$ leitor nota não apenas os personagens como também o espaço. Este é essencial na penúltima página, pois a igreja reproduzida ao fundo é, de fato, a igreja da Sé do Rio de Janeiro, no século XIX. Confrontar a ilustração dela com uma foto antiga da época pode gerar reflexões pertinentes sobre a adaptação em sala de aula.

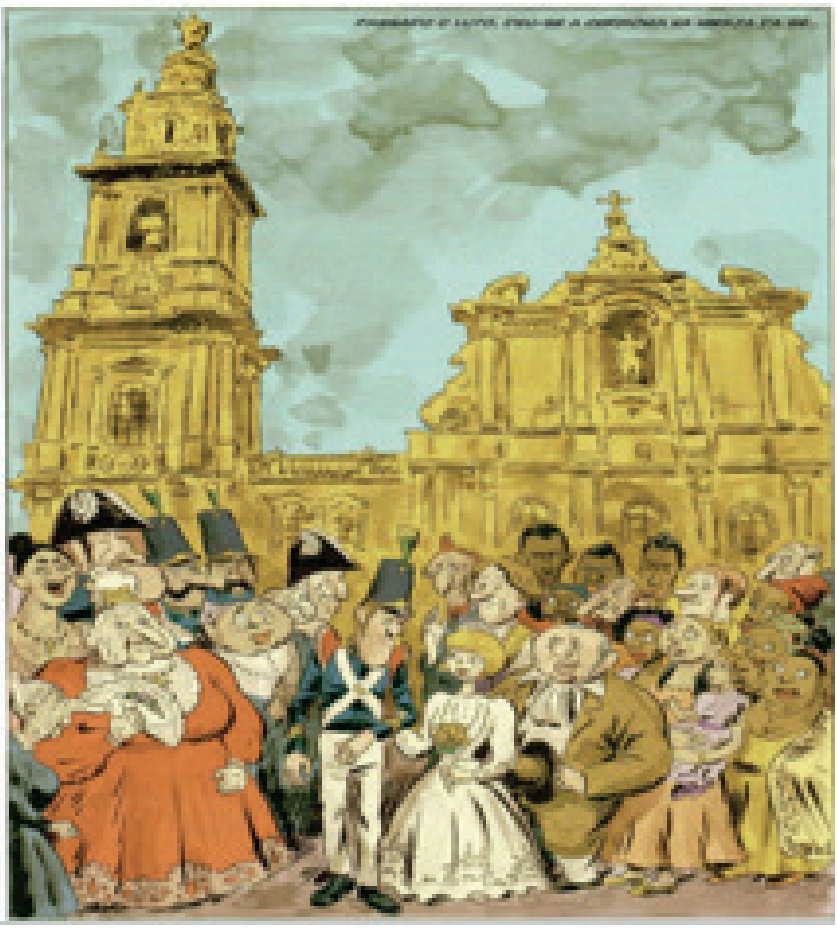

Figura 7 - Penúltima página da adaptação de Rosa e Jaf (2010, p. 73).

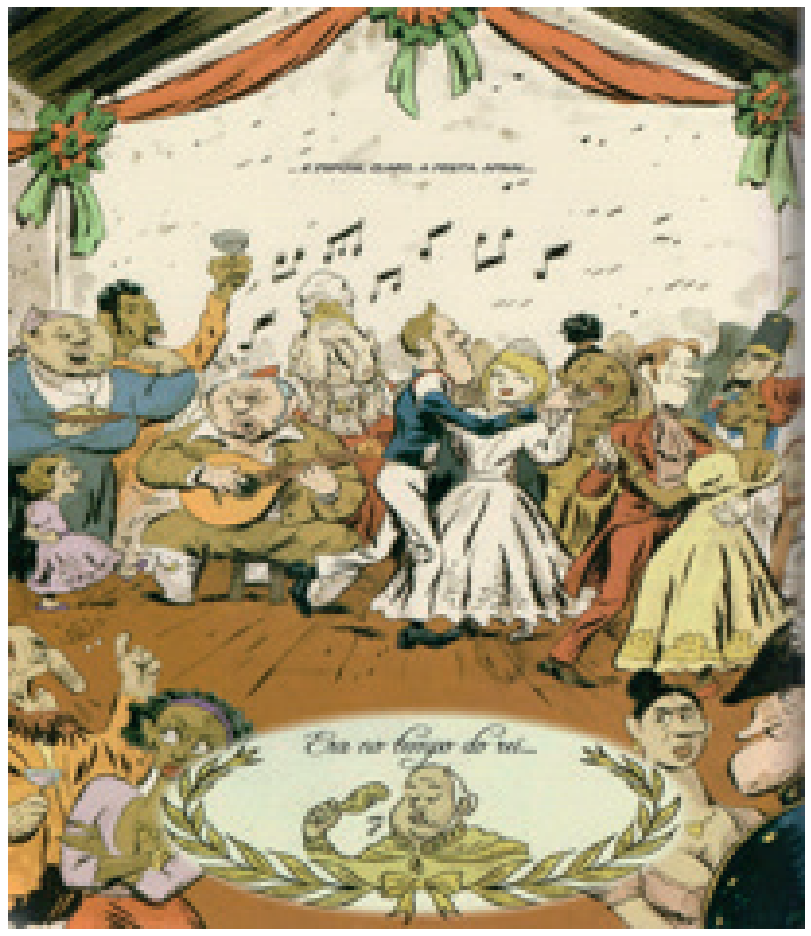

Figura 8 - Última página da adaptação de Rosa e Jaf (2010, p. 74).

Ademais, no texto em prosa, o leitor é poupado de saber sobre os demais acontecimentos subsequentes, já que são tristes, segundo o narrador. $\mathrm{Na}$ adaptação, o recurso utilizado é a reprodução de um quadro adicional, posto como um arremate do enredo visual. O último quadro repete elementos presentes no primeiro. Porém, no lugar de um batismo, a celebração é o próprio casamento de Leonardo e Luisinha. Novamente, todos dançam ao som da música tocada por LeonardoPataca. Como um fechamento ou despedida, a célebre frase de abertura do romance é reproduzida mais uma vez, assim como a figura de Dom João VI. De modo estereotipado, ele aparece envolto em folhas de louro e comendo uma coxa de frango, uma imagem sedimentada pelo senso comum. Na obra 1808: A vinda da corte portuguesa para o Brasil, a

asas da palavra
VOL. 16 | N.2 | DEZ.2019 ISSN $1415-7950$ historiadora Mariana Muaze (2011) explica sobre os antecedentes dessa imagem estereotipada: 
[...] o livro História de Portugal no final do século $X I X$, de Oliveira Martins, aquele que sedimentou uma imagem de Dom João VI como um 'desengonçado comedor de frangos', ainda hoje bastante presente no senso comum e reafirmada em filmes e séries de TV. Tais trabalhos têm em comum uma visão deletéria da corte e da vida nos trópicos [...] (2011, p. 32, grifos da autora)

O trabalho de pesquisa abrangido pela adaptação é, mais uma vez, delineado e o tempo narrado pelo romance é reelaborado para o leitor contemporâneo.

A análise dos elementos próprios aos quadrinhos, a descrição de cada um desses momentos e os trechos do romance formam uma tríade importante para conceber a estrutura da adaptação, de modo a valorizar os aspectos multimodais da HQ. Por fim, baseando-se nas ideias de Lielson Zeni (2009), discutidas em Quadrinhos na Educação: da rejeição à prática, é possível compreender que, em termos metodológicos, durante a leitura de uma adaptação:

[...] precisamos ser capazes de entender minimamente as técnicas utilizadas por essa obra, como funciona uma história em quadrinhos, a que tipo de informações devemos dar atenção, o que a torna realmente uma obra quadrinizada e não apenas ilustrações com texto ou um texto ilustrado. Ou seja: uma adaptação deve ser considerada como obra autônoma. (2009, p. 131)

\section{A ADAPTAÇÃO EM SALA DE AULA: INDICAÇÕES PRÁTICAS}

Os aspectos multimodais que compõem os mais variados tipos de textos apresentados diariamente aos estudantes nas aulas de língua portuguesa devem ser apontados, explicados e valorizados. Dois propósitos elementares justificam essas ações em sala de aula: promover a reflexão sobre a composição multifacetada que as produções textuais vêm adquirindo na era tecnológica e digital e estimular a recepção e produção consciente desses textos. Logo, professor e aluno carecem de boa formação:

Lemke (2000, p. 269) ressalta que multiletramentos e gêneros multimodais podem ser ensinados, mas é necessário que "professores e alunos estejam plenamente conscientes da existência de tais aspectos: o que eles são, para que eles são usados, que recursos empregam, como eles podem ser integrados um ao outro, como eles são tipicamente formatados, quais seus valores e limitações. (LEMKE, 2000, p. 269 apud DIONÍSIO, 2011, p. 140) 
A relevância da adaptação em HQ selecionada para a prática dos multiletramentos na escola advém da sua própria estrutura multimodal, verificada ao longo da análise. A leitura dela não está limitada em responder se o clássico deve ou não ser substituído - este não é pontochave do debate - mas está empenhada na consideração dos modos distintos de ler, ver, compreender e significar proporcionados pelas novas linguagens que integram diferentes textos. O caráter visual da HQ favorece ainda mais esse tipo de trabalho, como assinala Patrícia Pina (2014), no capítulo "A literatura em quadrinhos e a formação do leitor hoje", presente na obra Quadrinhos e literatura: diálogos possíveis:

[...] há um processo de intensificação e amplificação dessas mesmas competências, exatamente pelo hibridismo da linguagem quadrinística, pela interação verbal/ não verbal, o que pode solicitar do leitor uma atenção maior a detalhes e a capacidade de ler simultaneamente linguagens diferentes em hibridização. A natureza artística dos quadrinhos, essencialmente lúdica, viabiliza, dessa forma, uma formação leitora mais complexa, mais criativa (2014, p. 215)

Adiante, para reafirmar a relevância da adaptação selecionada para a prática dos multiletramentos na Educação Básica, algumas indicações de seu uso em sala de aula são realizadas. Elas seguem a seguinte lógica: a) discussão conceitual sobre "clássicos"e "adaptações"; b) aproximação da linguagem quadrinística e suas peculiaridades; c) comparação entre original e adaptação e, por fim, d) produção de uma transposição. Memórias de um Sargento de Milícias em HQ - Proposta de trabalho (Ensino Médio)

\begin{tabular}{|c|l|l|l|}
\hline Aulas & \multicolumn{1}{|c|}{ Tema } & \multicolumn{1}{c|}{$\begin{array}{l}\text { Indicações para o Professor de Língua } \\
\text { Portuguesa }\end{array}$} \\
\hline $\mathbf{0 1}$ & $\begin{array}{l}\text { Os clássicos da } \\
\text { literatura e suas } \\
\text { adaptações }\end{array}$ & $\begin{array}{l}\text { "O que são obras clássicas? Vocês já leram } \\
\text { essas obras? O que são obras adaptadas? Quais } \\
\text { adaptações vocês conhecem? As adaptações } \\
\text { devem ser, necessariamente, fiéis aos originais } \\
\text { ou elas têm autonomia?" Essas perguntas são } \\
\text { norteadoras para uma discussão inicial entre } \\
\text { professor e alunos. Depois, o docente apresenta } \\
\text { para a sua turma trechos de diferentes tipos de } \\
\text { adaptações de obras da literatura. }\end{array}$ \\
\hline $\mathbf{0 3}$ & O romance de Manuel \\
\hline $\mathbf{0 4}$ & Antonio de Almeida & $\begin{array}{l}\text { Em roda, os alunos devem ler, de forma } \\
\text { alternada e em voz alta, o primeiro capítulo do } \\
\text { romance Memórias de um Sargento de Milícias. } \\
\text { O professor sana dúvidas pontuais do texto e } \\
\text { realiza exposição teórica sobre o romance. }\end{array}$ \\
\hline
\end{tabular}




\begin{tabular}{|c|c|c|}
\hline \multicolumn{3}{|c|}{$\begin{array}{c}\text { Memórias de um Sargento de Milícias em HQ - Proposta de trabalho (Ensino } \\
\text { Médio) }\end{array}$} \\
\hline Aulas & Tema & $\begin{array}{c}\text { Indicações para o Professor de Língua } \\
\text { Portuguesa }\end{array}$ \\
\hline 05 & \multirow{2}{*}{$\begin{array}{l}\text { "Ler quadrinhos é ler } \\
\text { sua linguagem" }\end{array}$} & \multirow[b]{2}{*}{$\begin{array}{l}\text { O professor apresenta aos alunos a adaptação } \\
\text { da obra Memórias de um Sargento de Milicias } \\
\text { em HQ, elaborada por Rodrigo Rosa e Ivan Jaf } \\
\text { (2010), por meio de datashow. A discussão sobre } \\
\text { ela começa pela capa e alcança as duas primeiras } \\
\text { páginas. Algumas perguntas devem ser lançadas } \\
\text { aos estudantes: "O que vocês veem representado } \\
\text { na capa da HQ? A partir dessa ilustração, o que } \\
\text { podemos inferir sobre a história a ser contada } \\
\text { e mostrada? Agora, como o protagonista é } \\
\text { caracterizado na primeira página? O que ele } \\
\text { está fazendo? Como é a aparência dele? Qual é } \\
\text { o efeito produzido por essa aproximação (close } \\
\text { up) na representação do bebê? E a história dos } \\
\text { pais deles? Qual é o recurso utilizado para } \\
\text { simbolizar o recuo temporal nos quadrinhos?" } \\
\text { Tais questões podem estimular o debate em sala. }\end{array}$} \\
\hline 06 & & \\
\hline 07 & \multirow{2}{*}{$\begin{array}{l}\text { O romance } \quad \text { e } \\
\text { sua } \\
\text { comparações }\end{array}$} & \multirow{2}{*}{$\begin{array}{l}\text { Nestas aulas, o primeiro capítulo do romance é } \\
\text { confrontado com as duas primeiras páginas da } \\
\text { adaptação em quadrinhos, a fim de que os alunos } \\
\text { compreendam as possibilidades imagéticas } \\
\text { trazidas pela linguagem dos quadrinhos. }\end{array}$} \\
\hline 08 & & \\
\hline 09 & \multirow{2}{*}{$\begin{array}{l}\text { Produção } \\
\text { (individual) }\end{array}$} & \multirow[b]{2}{*}{$\begin{array}{l}\text { Aula reservada para que os alunos redijam uma } \\
\text { breve produção escrita que compare trechos do } \\
\text { primeiro capítulo do romance e as duas primeiras } \\
\text { páginas da HQ, apontando quais elementos } \\
\text { quadrinísticos foram empregados para recontar } \\
\text { o clássico. }\end{array}$} \\
\hline 10 & & \\
\hline 11 & \multirow{2}{*}{$\begin{array}{l}\text { Proposta de trabalho } \\
\text { final (em grupo) }\end{array}$} & \multirow{2}{*}{$\begin{array}{l}\text { O professor propõe uma tarefa aos alunos: em } \\
\text { grupos, devem produzir uma adaptação a partir } \\
\text { do primeiro capítulo do romance. }\end{array}$} \\
\hline 12 & & \\
\hline 13 & \multirow[t]{2}{*}{ Fechando a proposta } & \multirow{2}{*}{$\begin{array}{l}\text { Devolutiva da produção escrita feita nas aulas } \\
09 \text { e } 10 \text {. Adiante, os alunos apresentam seus } \\
\text { trabalhos para toda a classe. }\end{array}$} \\
\hline 14 & & \\
\hline
\end{tabular}

\section{ÚLTIMAS CONSIDERAÇÕES}

Há outros modos de ler as obras clássicas atualmente? Esse questionamento, suscitado na introdução deste artigo, desencadeou discussões acerca de uma possibilidade, entre outras tantas, de considerar o valioso uso da adaptação em quadrinhos do romance Memórias de um Sargento de Milícias como caminho para o almejado desenvolvimento de práticas de leitura efetivas na escola. A primeira seção apresentou três conceitos importantes: multimodalidade, multiletramentos e adaptação. A partir deles, o objeto de análise pôde 
ser estudado enquanto artefato multimodal complexo, constituído pelo imbricamento de diferentes modos de linguagem e, portanto, responsável pela construção de novos significados verbais e não verbais para a obra de Manuel Antônio de Almeida. A composição quadrinística exigiu uma ampliação da capacidade de compreender tal formulação híbrida. A adaptação, consequentemente, pôde ser contemplada para além do critério de fidelidade, sendo observada enquanto processo e produto. Essa dualidade esclareceu o quanto esse tipo de produção mesclou, em sua formulação, referência à obra anterior e empreendimento de recursos artístico-literários que pudessem reinventá-la. A segunda seção demonstrou alguns desses procedimentos e respondeu ao primeiro objetivo deste trabalho: verificar quais os recursos multimodais mobilizados pelos autores Rodrigo Rosa e Ivan Jaf na adaptação.

Quadrinização das principais cenas do romance (como o batizado de Leonardinho e, já em sua fase adulta, seu casamento); uso de balões para representar os diálogos do romance (em detrimento de descrições excessivas); modificação do formato dos quadros e uso de cores de aspecto envelhecido para simbolizarem o recuo temporal necessário para contar a história dos pais do futuro sargento; estudo das pinturas de Debret como referências para a narrativa visual retratar " $O$ tempo do rei" e a representação caricata do protagonista foram alguns dos aspectos multimodais estudados. O ambiente escolar pode ser propício para promoção de reflexões sobre tais especificidades. Por essa razão, a terceira seção teceu indicações para o uso dela em sala de aula, respondendo, diante disso, ao segundo objetivo deste artigo: discutir a relevância da adaptação selecionada para a prática dos multiletramentos na escola.

\section{REFERÊNCIAS}

ALMEIDA, Danielle Barbosa Lins de. Do Texto às Imagens: As novas Fronteiras do letramento visual. In: PEREIRA, Regina Celi. ROCCA, Pilar (Orgs). Linguística Aplicada: um caminho com diferentes acessos. 1ª ed. São Paulo: Contexto, 2009.

ALMEIDA, Manuel Antônio de. Memórias de um Sargento de Milícias. Biografia e introdução de Afrânio Coutinho. Rio de Janeiro: Ediouro; São Paulo: Publifolha, 1997.

CALVINO, Italo. Por que ler os clássicos. Trad. Nilson Moulim. São Paulo: Companhia das Letras, 2007.

DIONISIO, Ângela Paiva. Gêneros Textuais e Multimodalidade. In: KARWOSKI, A. M; GAYDECZKA, B.; BRITO, K. S. (Orgs.) Gêneros textuais: reflexões e ensino. São Paulo: Parábola Editorial, 2011. 
ECO, Umberto. Quando muda a matéria. In: Quase a mesma coisa. Editora Record, 2007.

EISNER, Will. Quadrinhos e arte sequencial: princípios e práticas do lendário cartunista. Trad. Luis Carlos Borges, Alexandre Boide. $-4^{\mathrm{a}}$ ed. - São Paulo: Editora WMF Martins Fontes, 2010.

HUTCHEON, Linda. Uma teoria da adaptação. Santa Catarina: Editora da UFSC, 2013.

JAF, Ivan; ROSA, Rodrigo. Memórias de um Sargento de Milícias. Adaptação do romance de Manuel Antônio de Almeida (Coleção Clássicos em HQ). Ivan Jaf (roteiro); Rodrigo Rosa (ilustrações). 1 ${ }^{\mathrm{a}}$ ed. São Paulo: Ática, 2010.

$\mathrm{KOCH}$, Ingedore Villaça; ELIAS, Vanda Maria. Ler e compreender os sentidos dos textos. $2^{\mathrm{a}}$ reimp. São Paulo: Contexto, 2008.

KRESS, Gunther; VAN LEEUWEN, Theo V. Multimodal discourse: The modes and media of contemporary communication, 2001.

MARCUSCHI, Luiz Antônio. Produção textual, análise de gêneros e compreensão. São Paulo: Parábola, 2008.

MUAZE, Mariana. 1808: A vinda da corte portuguesa para o Brasil. In: História do Brasil II. v. 1 / João Carlos Escosteguy Filho, Mariana Muaze, Ricardo Salles. Rio de Janeiro: Fundação CECIERJ, 2011.

OLIVEIRA, Cristina de. Quadrinhos, literatura e o jogo intertextual. In: RAMOS, Paulo; VERGUEIRO, Waldomiro; FIGUEIRA, Diego (Orgs.). Quadrinhos e literatura: diálogos possíveis. São Paulo: Criativo, 2014.

PIMENTA, Sônia; SANTOS, Zaira Bonfante dos. Linguística Textual e a perspectiva sociossemiótica da linguagem: orquestrações multimodais de significados. In: CAPISTRANO JÚNIOR; R.; LINS, M. P. P; ELIAS, V, M. (Orgs.). Linguística textual: diálogos interdisciplinares. São Paulo: Labrador/ PPGEL-UFES, 2017.

PINA, Patrícia Kátia da Costa. A literatura em quadrinhos e a formação do leitor hoje. In: RAMOS, Paulo; VERGUEIRO, Waldomiro; FIGUEIRA, Diego (Orgs.). Quadrinhos e literatura: diálogos possíveis. São Paulo: Criativo, 2014.

RAMOS, Paulo. A leitura dos quadrinhos. São Paulo: Contexto, 2012.

ROJO, Roxane. Pedagogia dos multiletramentos: diversidade cultural e de linguagens na escola. In: ROJO, Roxane. Multiletramentos na escola. São Paulo: Parábola Editorial, v. 90, n. 2, 2012.

VELOSO, Francisco O. Dourado. Pesquisa em multimodalidade: por uma abordagem sociossemiótica. In: GONÇALVES, A. V.; SILVA, W. R.; GÓES, M. L. S. (Orgs.). Visibilizar a linguística aplicada: abordagens teóricas e metodológicas. Campinas, SP: Pontes editores, 2014.

ZENI, Lielson. Literatura em Quadrinhos. In: VERGUEIRO, W.; RAMOS, P. (Orgs.). Quadrinhos na educação: da rejeição à prática. São Paulo: Contexto, 2009. 
Recebido em 04 Out 2019 | Aprovado em 04 Nov 2019

Renata Lopes da SILVA

Graduada em Letras (Habilitação em Língua Portuguesa) pela Escola de Filosofia, Letras e Ciências Humanas da Universidade Federal de São Paulo (UNIFESP). Mestranda em Estudos Literários no Programa de Pós-graduação em Letras na mesma Instituição. Em sua pesquisa atual, estuda adaptações de obras de Machado de Assis para a literatura de cordel.E-mail: renata lopes06@hotmail.com

\section{Francine Fernandes Weiss RICIERI}

Docente da Universidade Federal de São Paulo (UNIFESP-Guarulhos). Doutora pela UNICAMP em Literatura Brasileira e mestre pela UNESP em Teoria Literária e Literatura Comparada. Organizou e apresentou a Antologia da Poesia Simbolista e Decadente Brasileira (Lazúli/ Companhia Editora Nacional). Com Marcia Lígia Guidin e Lúcia Granja, preparou a coletânea de ensaios Machado de Assis: ensaios da crítica contemporânea (Editora da UNESP). Autora de Imagens do poético em Alphonsus de Guimaraens (Editora da UNICAMP/ EDUSP). E-mail: francinericieri@gmail. com 